\title{
Hyperglycemia simultaneously induces initial caries development and enhances spontaneous occlusal surface wear in molar teeth related to parotid gland disorder in alloxan-induced diabetic rats
}

\author{
Taiki Nishimoto ${ }^{1}$, Yasushi Kodama ${ }^{{ }^{*}}$, Tetsuro Matsuura ${ }^{2 *}$, Kiyokazu Ozaki ${ }^{2}$, and \\ Yoshihiko Taniguchi ${ }^{1}$ \\ ${ }^{1}$ Laboratory of Clinicopathological Therapeutics, Faculty of Pharmaceutical Sciences, Hiroshima International University, 5-1-1 \\ Hirokoshingai, Kure, Hiroshima 737-0112, Japan \\ ${ }^{2}$ Laboratory of Pathology, Faculty of Pharmaceutical Sciences, Setsunan University, 45-1 Nagaotoge-cho, Hirakata, Osaka 573-0101, \\ Japan
}

\begin{abstract}
Diabetes and salivary gland dysfunction are major factors that induce dental caries in experimental animals, but there are no reports analyzing the association of dental caries and salivary glands in an animal model of diabetes mellitus (DM). To clarify the initial development of dental caries and preceding salivary gland disorder, we performed a histopathological analysis on teeth and salivary glands in diabetic Wistar rats 7 weeks after alloxan treatment (DM group) in comparison with nondiabetic rats (Non-DM group) and functional analysis on saliva secretion during the experimental period. Pilocarpine-induced salivary fluid secretion in diabetic rats gradually decreased with continuous hyperglycemia from immediately after alloxan treatment to the time of autopsy. Histopathologically, Oil Red O-positive lipid droplets accumulated in the acinar cells of the parotid gland. No tooth was stereoscopically defined as having dental caries in any of the rats in either group; however, the external appearance remarkably changed owing to occlusal wear in almost all molars in the DM group. The initial lesions of dental caries, appearing as micro-defects in dentin with bacterial colonization on the molar surface, were identified using histopathological analysis, and the incidence in the DM group was more than twice that in the Non-DM group. In conclusion, hyperglycemia simultaneously induces initial caries development and enhances spontaneous occlusal wear in molar teeth of Wistar rats 7 weeks after alloxan treatment. The parotid gland dysfunction caused by hyperglycemia may be mostly involved in the pathogenesis of occlusal wear as well as in dental caries in this diabetic model. (DOI: 10.1293/tox.2016-0054; J Toxicol Pathol 2017; 30: 47-55)
\end{abstract}

Key words: diabetes, hyperglycemia, dental caries, hyposalivation, occlusal wear, rat

\section{Introduction}

Dental caries occur in the presence of pathogenic bacteria and sugar in a predisposing host ${ }^{1}$. Thus far, since the onset of naturally occurring dental caries has not been reported in rodent models, the researchers have used a cariogenic diet containing large amounts of sugar and/or an inoculation of infectious cariogenic bacteria into the oral cavity to induce dental caries. Recently, we reported the development of dental caries in a caries-susceptible strain fed a noncariogenic diet with a low sugar concentration ${ }^{2}$. In addition, we clarified that diabetes is an important factor

Received: 10 August 2016, Accepted: 7 October 2016

Published online in J-STAGE: 6 November 2016

*Corresponding authors:

Y Kodama (e-mail: y-kodama@ps.hirokoku-u.ac.jp)

T Matsuura (e-mail: matsuura@pharm.setsunan.ac.jp)

(C)2017 The Japanese Society of Toxicologic Pathology

This is an open-access article distributed under the terms of the Creative Commons Attribution Non-Commercial No Derivatives (by-ncnd) License $<\mathrm{http}: / /$ creativecommons.org/licenses/by-nc-nd/4.0/> . inducing dental caries under the given noncariogenic $\operatorname{diet}^{3,4}$.

Salivary gland dysfunction in Sjögren's syndrome and radiation therapy are the major factors causing onset of dental caries in humans and experimental animals ${ }^{5-7}$. Hyposalivation and morphological abnormality of the salivary gland also occur in diabetic patients and animals ${ }^{8-12}$. Diabetes may be significantly associated with salivary gland dysfunction. Thus, the development of dental caries in a diabetic animal model may be correlated with salivary gland disorder; however, there are no reports sufficiently analyzing the relationship between dental caries and salivary gland disorder. To test this hypothesis, the development of dental caries and salivary gland disorder should be simultaneously analyzed in the same diabetic animals.

Alloxan (AL) is one of the chemicals that induce loss of pancreatic $\beta$-cells and cause a severe hyperglycemic condition, thereby inducing diabetes mellitus in animals. In AL-treated rats, progressive molar caries with collapse of the dental crown were observed after a 13-week hyperglycemic period ${ }^{13}$. Hyposalivation and morphological abnormality of the salivary gland were also reported after $\mathrm{AL}$ 
treatment ${ }^{14-16}$. However, to our knowledge, the association between dental caries and salivary gland disorders has not been investigated in AL-induced diabetic models or in other animal models of diabetes.

Although severe caries uniformly develop in rats at 13 weeks after the onset of hyperglycemia induced by AL treatment, there are no lesions present in the initial 4 weeks following induction of hyperglycemia ${ }^{13}$. Therefore, primary dental caries are expected to develop between 4 and 13 weeks after AL treatment in this model. In addition, we hypothesized that the salivary gland abnormalities in ALtreated diabetic rats might precede dental caries formation at an earlier stage. Thus, in this study, onset of the dental caries induced by AL treatment was estimated at 7 weeks (nearly half of 13 weeks) after hyperglycemia, and the autopsy point was set at this time. To this end, we examined the morphology of the teeth and salivary glands and performed serial measurements for evaluating salivary secretion ability; we also clarified the pathogenetic relationship between the dental caries development and salivary gland dysfunction in this diabetic model.

\section{Materials and Methods}

\section{Animals and housing conditions}

The rats were handled according to the principles outlined in the Guide for the Care and Use of Laboratory Animals by the Committee for Animal Experiments of Hiroshima International University and the Japanese Association for Laboratory Animal Science. Male Wistar (Crlj:WI) rat pups born to female SPF Wistar rats supplied by Charles River Laboratories Japan, Inc. (Yokohama, Japan), were used in this study. They were reared in a barrier-sustained animal room maintained at a temperature of $23 \pm 2{ }^{\circ} \mathrm{C}$ and a relative humidity of $55 \pm 10 \%$ with 12 -h light/dark cycles and ventilation at least 10 times/h with high-efficiency particulate air-filtered fresh air. All rats were housed and reared in fiber-reinforced plastic (FRP) cages with a stainless (SUS304) wire-mesh floor. Rats had free access to tap water and a widely used noncariogenic standard pelletized diet for experimental mice and rats (CLEA Rodent Diet CE2, CLEA Japan, Inc., Tokyo, Japan).

\section{Experimental design}

The experimental design is shown in Fig. 1. A total of 23 rats were randomly divided into 2 groups: diabetic rats (DM group; $n=13$ ) and nondiabetic rats (Non-DM group; $\mathrm{n}=10$ ) at 7 weeks of age. In the DM group, a single dose of 50 $\mathrm{mg} / \mathrm{kg}$ of AL (Sigma-Aldrich Japan, Tokyo, Japan) was administered via the tail vein, whereas the rats in the Non-DM group were administered a single dose of $0.9 \%$ saline. All of the rats were euthanized at 14 weeks of age, and their teeth and salivary glands were histopathologically examined.

\section{Glucosuria and glycemia monitoring}

Urinary glucose levels were measured semiquantitatively with a urine test paper (Wako Pure Chemical Indus-

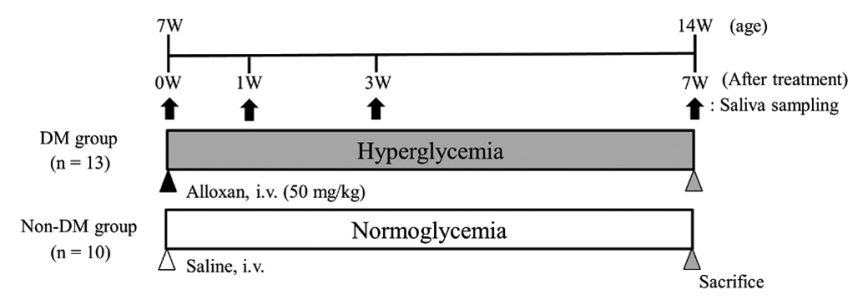

Fig. 1. Study design.

tries, Osaka, Japan) using fresh urine. Blood glucose levels were also measured semiquantitatively by the glucose oxidase method (Glutest PRO R, Sanwa Kagaku Kenkyusho, Aichi, Japan) using non-fasting blood samples collected from the tail vein. Urinary and blood glucose levels were measured at 0, 1, 3 and 7 weeks after AL treatment. Samples of blood from the tail vein and fresh urine were collected between 13:00 and 16:00. Hyperglycemia and glucosuria were defined as glucose levels greater than $200 \mathrm{mg} / \mathrm{dL}$ and 250 $\mathrm{mg} / \mathrm{dL}$, respectively.

\section{Measurement of food intake}

Food intake over a 24-hour period was measured using rats from each group (DM group, $\mathrm{n}=8$; Non-DM group, $\mathrm{n}=$ 5 ) at $0,1,3$, and 7 weeks after AL treatment.

\section{Saliva collection}

Saliva secretion was induced by subcutaneous injection of pilocarpine ( $2 \mathrm{mg} / \mathrm{kg}$ body weight). The saliva was collected using cotton balls between 3 to 8 min after pilocarpine injection under deep anesthesia with pentobarbital ( $25 \mathrm{mg} / \mathrm{kg}$ body weight, i.p.). The total weight of the secreted saliva (difference in the weight of the cotton balls before and after collection) was measured at $0,1,3$, and 7 weeks after AL treatment.

\section{Stereoscopic and soft X-ray examination of the man- dibular and maxillary molars}

At the end of study period, the animals were euthanized by exsanguination from the abdominal aorta under deep anesthesia induced using isoflurane. Subsequently, the mandible and maxilla were removed and fixed in $10 \%$ neutral buffered formalin solution ( $\mathrm{pH} 7.4)$. After a 24-h fixation, the occlusal, buccolingual, and proximal surfaces of all teeth were examined under a binocular stereoscope. The stereoscopic change scores of each molar obtained using a binocular stereoscope were classified into 4 grades: grade 0 , no change in the molar tooth; grade 1 , mild wear of the cuspis dentis; grade 2, moderate wear of the cuspis dentis; grade 3 , severe wear of the cuspis dentis. Following stereoscopic examination, a soft X-ray examination was performed, and images of the mesiodistal plane were obtained at $35 \mathrm{kV}$ and $2 \mathrm{~mA}$ for $4 \mathrm{~min}$. The cusp height of the all molars on soft X-ray images was measured using the scale function in Adobe Photoshop Elements 9 (Adobe Systems, San Jose, CA, USA). 


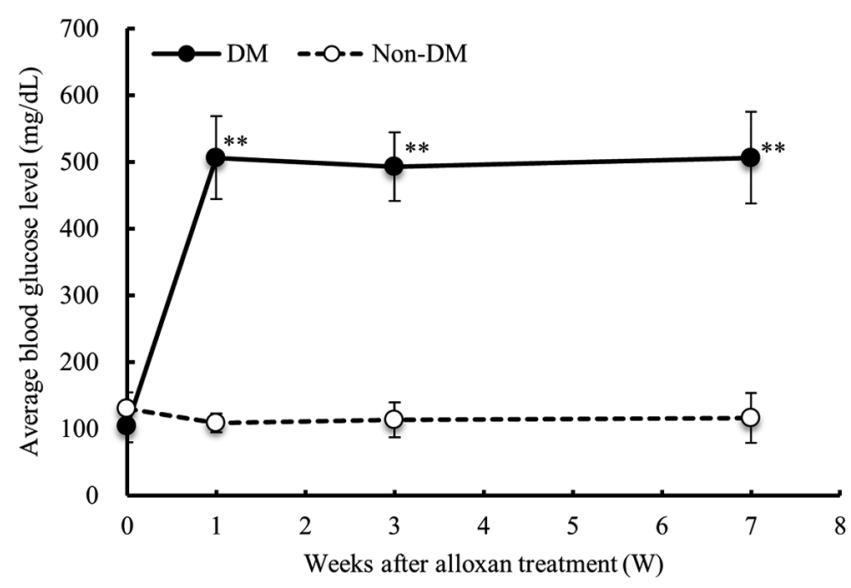

Fig. 2. The blood glucose changes in the DM and Non-DM groups. Severe hyperglycemia ( $>400 \mathrm{mg} / \mathrm{dL}$ ) persisted from the day after alloxan treatment in the DM group. The blood glucose level in the Non-DM group was consistently $<200 \mathrm{mg} / \mathrm{dL}$. The data are shown as the mean \pm SD. Significant difference compared with the Non-DM group $(* * \mathrm{P}<0.01)$.

\section{Histopathological examination}

For histopathological examination, the jaw, salivary glands, and tongue were removed and fixed in $10 \%$ neutral buffered formalin solution ( $\mathrm{pH}$ 7.4). After formalin fixation for 24-h, the parotid gland, submandibular gland, and tongue, including the von Ebner's glands, were trimmed, dehydrated in a sequential ethanol series by using an automated processor, and embedded in paraffin. The mandible and maxilla were decalcified in K-CX (Falma Co., Ltd., Tokyo, Japan) for $24 \mathrm{~h}$ and immersed in a 1:1 mixture of $10 \%$ formic acid solution and neutral buffered formalin solution for 5 days after formalin fixation. After decalcification, the specimens were trimmed, dehydrated, and embedded in paraffin. These paraffin tissue sections $(5-\mu \mathrm{m}$ thick) were stained with hematoxylin/eosin. The vacuolation scores of sections of each salivary gland were classified into 5 grades: grade 0 , no or rare vacuoles; grade 1 , small vacuoles present in less than $50 \%$ of the total gland; grade 2 , small vacuoles present in more than $50 \%$ of the total gland; grade 3 , in addition to the small vacuoles, large vacuoles present in less than $50 \%$ of the total gland; grade 4 , large vacuoles present in more than $50 \%$ of the total gland.

To determine the contents of the vacuoles observed within the salivary glands, a part of the left parotid gland and a part of the tongue, including the von Ebner's glands, were embedded in OCT Compound (Sakura Finetek Japan Co., Ltd., Tokyo, Japan) for preparing frozen tissue specimens, and these frozen tissue sections $(10-\mu \mathrm{m}$ thick) were stained with Oil Red O.

\section{Statistical analysis}

The differences between the groups in mean blood glucose levels, body weight, food intake, saliva weight, and cusp height were determined using a Student's t-test or Welch's t-test. The chi-square test was used to compare the

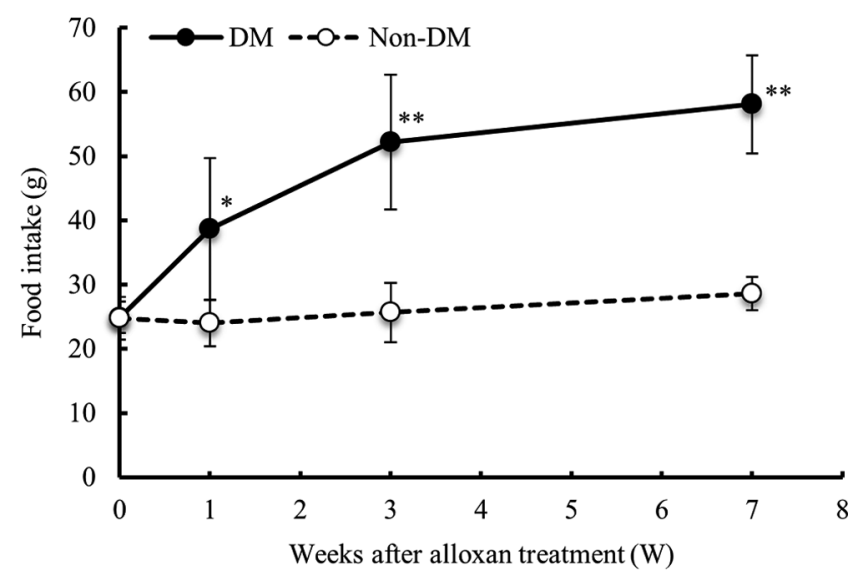

Fig. 3. The food intake changes in the DM and Non-DM groups. The data are shown as the mean $\pm \mathrm{SD}$. Significant difference compared with the Non-DM group $(* \mathrm{P}<0.05 ; * * \mathrm{P}<0.01)$.

incidence of macroscopic and histopathologic changes in the molars. The Mann-Whitney test was used to compare the mean lesion scores of the salivary glands between the groups. $\mathrm{P}<0.05$ was regarded as statistically significant.

\section{Results}

Glucosuria, glycemia, and general condition monitoring

The mean blood glucose levels of each group are shown in Fig. 2. All rats in the DM group showed severe hyperglycemia $(>400 \mathrm{mg} / \mathrm{dL})$ and glucosuria $(>2,000 \mathrm{mg} /$ $\mathrm{dL}$ ) from the day after AL injection till the end of the study. In contrast, glucosuria was not observed in any rat in the Non-DM group, and normoglycemia persisted throughout the study (Fig. 2). The mean body weight in the DM group decreased over time after AL treatment and was significantly lower than that in the Non-DM group at 3 and 7 weeks following treatment. However, the mean food intake after AL treatment in the DM group was significantly higher than that in the Non-DM group at each time point and at the final time point was more than twice that of the Non-DM group (Fig. 3). All of the rats used in this study survived until the end of the experimental period.

\section{Weight of secreted saliva}

The changes in the mean weights of pilocarpine-induced saliva in each group are shown in Fig. 4. The mean weight of secreted saliva after AL treatment in the DM group was significantly lower than that in the Non-DM group at each time point, and the final weight at 7 weeks after AL treatment was less than $50 \%$ of the weight in the Non-DM group. In the Non-DM group, the mean total saliva weight at $0,1,3$, and 7 weeks after treatment was $0.71,0.91$, 1.14 , and $1.25 \mathrm{~g}$, respectively, and showed a gradual increase over time. In contrast, a decreasing trend $(0.77,0.62,0.66$, and $0.53 \mathrm{~g}$ at $0,1,3$ and 7 weeks, respectively) was observed 


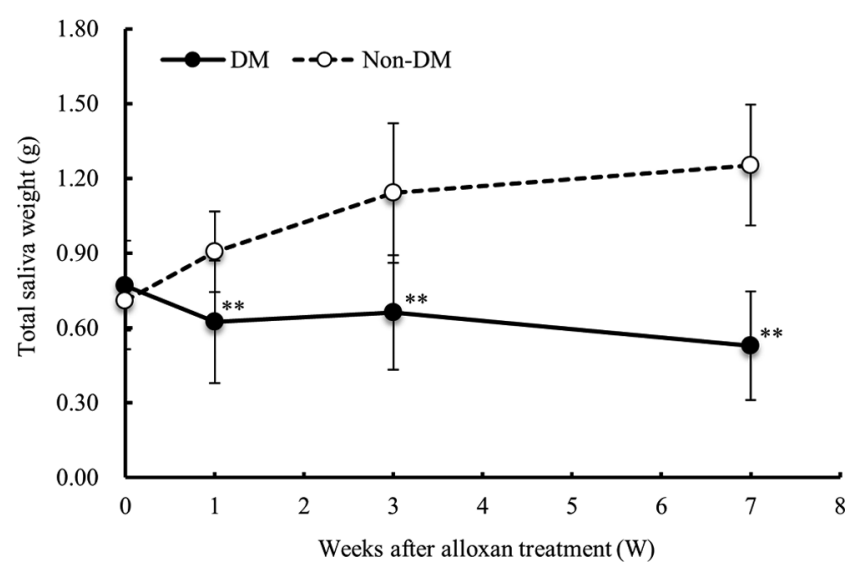

Fig. 4. The changes in total saliva weight in the DM and Non-DM groups. The data are shown as the mean \pm SD. Significant difference compared with the Non-DM group $(* * \mathrm{P}<0.01)$.

in the DM group; the values after AL treatment were also significantly lower than those in the Non-DM group at each time point $(\mathrm{P}<0.01)$.

\section{Macroscopic morphological examination by stereo- scope and soft $X$-ray film}

In this study, the typical manifestations of dental caries, such as collapse of the molar crown or a hole in the tooth surface with bacterial attachment, were not stereoscopically observed in any rats in the DM and Non-DM groups. Thus, no tooth was identified as having dental caries after stereoscopic morphological examination. Apart from the development of dental caries, external changes due to occlusal surface wear were apparent in almost all the teeth in the DM group, and the stereoscopic changes (maxilla, 98.7\%; mandible, $97.4 \%$ ) in the DM group were significantly more common than those in the Non-DM group (maxilla, $15.0 \%$; mandible, $30.0 \%$ ) (Table 1). Furthermore, these changes were remarkably enhanced in the DM group (Grade 1, 46.156.4\%; Grade 2, 38.5-43.6\%; Grade 3, 3.8-7.7\%) compared with the Non-DM group (Grade 1, 15.0-30.0\%; Grade 2, $0 \%$; Grade 3, 0\%) (Table 1, Fig. 5).

Soft X-ray examination showed wear of the enamel and dentin on the occlusal surface at the cusp, which was classified as a Grade-3 stereoscopic change under a microscope (Fig. 5e).

\section{Morphometric examination on occlusal surface wear of molar teeth}

The mean cusp heights of the maxillary and mandibular molars on the soft X-ray images are shown in Fig. 6. The mean cusp height in the DM group was approximately half that of the Non-DM group, and the difference between them was significant $(\mathrm{P}<0.01)$ (Fig. 6).

\section{Histopathological examination}

Mild dental caries that were not evident on stereoscopic examination could be identified on histological exami-

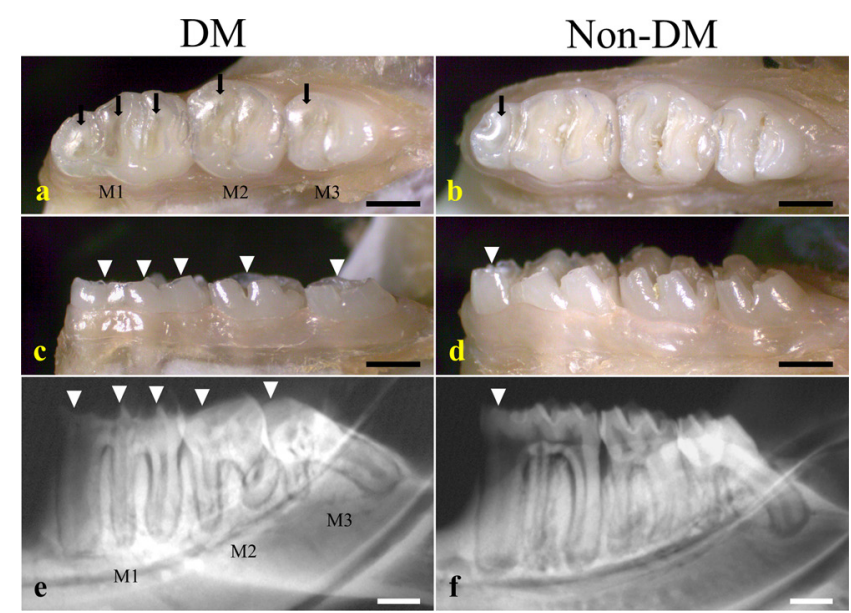

Fig. 5. Stereoscopic and soft X-ray images of the molars in the DM and Non-DM groups. M1, the 1st molar; M2, the 2nd molar; and M3, the 3rd molar. (a, b) Stereoscopic features of the overhead view of the mandibular molars in the DM group (a) and the Non-DM group (b). (a) Obvious occlusal wear is observed on the occlusal surface (arrows). (b) Mild occlusal wear is observed on a part of the occlusal surface of the 1st molar (arrow). (c, d) Stereoscopic lateral views of (a) and (b), respectively. (c) The height of molar cusps in the DM group is reduced (arrowheads) compared with that in the Non-DM group (d). (d) Mild occlusal wear is observed on the 1st molar (arrowhead). (e, f) Soft X-ray images of (c) and (d), respectively. (e) The disappearance of enamel and dentin at the cusp (arrowheads) is apparent. (f) The enamel and dentin of the cusp are clearly visible. Black scale bar $(\mathrm{a}-\mathrm{d})=1 \mathrm{~mm}$. White scale bar $(e, f)=1 \mathrm{~mm}$.
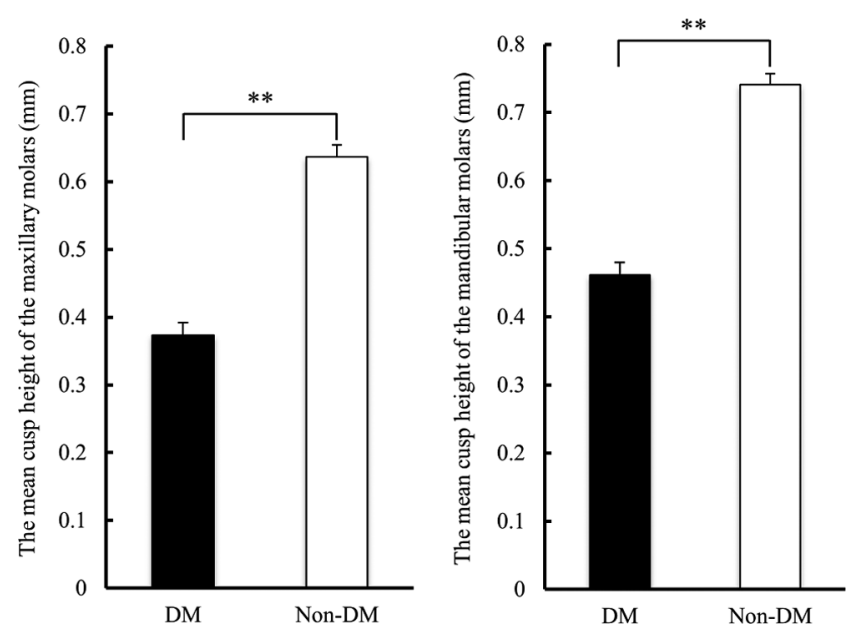

Fig. 6. The mean cusp height of the maxillary and mandibular molars in the DM and Non-DM groups. The data are shown as the mean \pm SD. Significant difference compared with the Non-DM group $(* * \mathrm{P}<0.01)$.

nation of serial sections of each molar in both groups. The incidence and severity of the dental caries in the DM group was significantly higher than that in the Non-DM group (Table 2). The majority of dental caries in both groups (DM, 
Table 1. Incidence and Grading of Stereoscopic Changes in the Molars

\begin{tabular}{llcr}
\hline & Group & DM $(\mathrm{n}=13)$ & Non-DM $(\mathrm{n}=10)$ \\
\hline Maxillary molars & No. examined & 78 & 60 \\
& No. of teeth with changes & $77(98.7 \%) * *$ & $9(15.0 \%)$ \\
& Grade 0 & $1(1.3 \%)$ & $51(85.0 \%)$ \\
& Grade 1 & $44(56.4 \%)$ & $9(15.0 \%)$ \\
& Grade 2 & $30(38.5 \%)$ & 0 \\
Grade 3 & $3(3.8 \%)$ & 0 & 60 \\
& No. examined & 78 & $18(30.0 \%)$ \\
& No. of teeth with changes & $76(97.4 \%) * *$ & $42(70.0 \%)$ \\
& Grade 0 & $2(2.6 \%)$ & $18(30.0 \%)$ \\
& Grade 1 & $36(46.1 \%)$ & 0 \\
& Grade 2 & $34(43.6 \%)$ & 0 \\
\hline
\end{tabular}

Significant difference compared with the Non-DM group $(* * \mathrm{P}<0.01)$.

Table 2. Incidence of Histopathologic Caries in the Molars

\begin{tabular}{|c|c|c|c|c|}
\hline \multirow{2}{*}{ Group } & \multicolumn{2}{|c|}{$\mathrm{DM}(\mathrm{n}=13)$} & \multicolumn{2}{|c|}{ Non-DM $(n=10)$} \\
\hline & Maxillary molars & Mandibular molars & Maxillary molars & Mandibular molars \\
\hline No. examined & 78 & 78 & 60 & 60 \\
\hline No. of teeth with caries & $28(35.9 \%) * *$ & $31(39.7 \%) * *$ & $5(8.3 \%)$ & $6(10.0 \%)$ \\
\hline Micro-defects of dentin with bacterial colonization & $25(32.1 \%)$ & $20(25.6 \%)$ & $5(8.3 \%)$ & $6(10.0 \%)$ \\
\hline Expanded defects of dentin with bacterial colonization & $3(3.8 \%)$ & $11(14.1 \%)$ & 0 & 0 \\
\hline
\end{tabular}

Significant difference compared with the Non-DM group $(* * \mathrm{P}<0.01)$

25.6-32.1\%; Non-DM, 8.3-10.0\%) were diagnosed as micro-defects in dentin with bacterial colonization (Fig. 7b), and the incidence in the DM group was more than twice that in the Non-DM group. Furthermore, advanced dental caries such as expanded defects with bacterial colonization (Fig. 7c) were detected at a low rate (3.8-14.1\%) in the DM group alone (Table 2). In some of the teeth with advanced caries, hypertrophic odontoblasts (Fig. 7e) and an abscess and/or necrosis of the dental pulp were observed (Fig. 7f). Meanwhile, mild to severe occlusal surface wear was histopathologically confirmed in almost all the teeth in the DM group, corroborating the results of morphometric examination for cusp height determined using soft X-ray photographs; the lesions were seen as a smooth dent in the occlusal surface of dentin. In many of the teeth with advanced occlusal wear, expanded dental caries were observed on the occlusal surface (Table 3). In addition, at the dentin-pulp junction just below the site of occlusal wear in the DM group, disappearance of the predentin layer or irregular arrangement of odontoblasts was observed accompanied by reparative dentin (Fig. 7d). Reparative dentin, where the dentinal tubules had locally become tortuous or unclear (Fig. 7e), was formed in almost all of the teeth in both DM and Non-DM groups (93.3-100\%), and yet the presence of bacteria in the dentinal tubules in the DM group (maxilla, 79.5\%; mandible, $76.9 \%$ ) was remarkably higher than that in the Non-DM group (maxilla, 30.0\%; mandible, 46.7\%; Table 4).

In the salivary glands, vacuolation of the acinar cells of the parotid gland and the von Ebner's gland was seen in the DM group, and the incidence and severity were sig-
Table 3. Occlusal Wear and Caries Grades of Each Molar in Individual Rats

\begin{tabular}{|c|c|c|c|c|c|c|c|c|c|c|c|c|c|}
\hline & & \multicolumn{6}{|c|}{ Maxillary molars } & \multicolumn{6}{|c|}{ Mandibular molars } \\
\hline & \multirow[b]{2}{*}{ No. } & \multicolumn{3}{|c|}{ Left } & \multicolumn{3}{|c|}{ Right } & \multicolumn{3}{|c|}{ Left } & \multicolumn{3}{|c|}{ Right } \\
\hline & & M1 & M2 & M3 & M1 & M2 & M3 & M1 & M2 & M3 & M1 & M2 & M3 \\
\hline \multirow{13}{*}{ DM } & 1 & 2 & 1 & 1 & 2 & 2 & 1 & 2 & 1 & 1 & 2 & 1 & 0 \\
\hline & 2 & 1 & 1 & 1 & 2 & 1 & 2 & 2 & 1 & 1 & 1 & 1 & 1 \\
\hline & 3 & 2 & 2 & 1 & 2 & 2 & 2 & 3 & 1 & 1 & 3 & 1 & 1 \\
\hline & 4 & 1 & 1 & 1 & 2 & 1 & 1 & 2 & 1 & 2 & 2 & 1 & 2 \\
\hline & 5 & 3 & 3 & 2 & 3 & 2 & 2 & 3 & 2 & 2 & 3 & 2 & 2 \\
\hline & 6 & 1 & 1 & 2 & 1 & 1 & 1 & 2 & 1 & 1 & 1 & 2 & 1 \\
\hline & 7 & 1 & 1 & 1 & 2 & 1 & 2 & 2 & 1 & 1 & 3 & 2 & 1 \\
\hline & 8 & 1 & 0 & 1 & 1 & 1 & 2 & 1 & 1 & 0 & 1 & 1 & 1 \\
\hline & 9 & 1 & 1 & 1 & 2 & 1 & 2 & 2 & 1 & 2 & 2 & 2 & 1 \\
\hline & 10 & 2 & 1 & 1 & 1 & 2 & 1 & 2 & 1 & 2 & 2 & 2 & 1 \\
\hline & 11 & 1 & 1 & 1 & 2 & 2 & 1 & 2 & 2 & 1 & 2 & 1 & 2 \\
\hline & 12 & 1 & 2 & 1 & 1 & 2 & 1 & 2 & 2 & 1 & 2 & 1 & 1 \\
\hline & 13 & 2 & 2 & 2 & 2 & 1 & 1 & 3 & 2 & 1 & 2 & 2 & 2 \\
\hline \multirow{10}{*}{$\begin{array}{l}\text { Non- } \\
\text { DM }\end{array}$} & 1 & 0 & 0 & 0 & 0 & 0 & 0 & 1 & 0 & 0 & 1 & 0 & 0 \\
\hline & 2 & 0 & 0 & 0 & 0 & 0 & 1 & 1 & 0 & 0 & 0 & 0 & 0 \\
\hline & 3 & 0 & 0 & 0 & 1 & 0 & 0 & 1 & 0 & 0 & 1 & 0 & 0 \\
\hline & 4 & 0 & 0 & 0 & 1 & 0 & 1 & 1 & 0 & 0 & 1 & 0 & 0 \\
\hline & 5 & 0 & 0 & 0 & 0 & 1 & 0 & 1 & 0 & 0 & 1 & 0 & 0 \\
\hline & 6 & 0 & 0 & 0 & 1 & 0 & 1 & 1 & 0 & 0 & 1 & 0 & 0 \\
\hline & 7 & 0 & 0 & 1 & 0 & 0 & 0 & 1 & 0 & 1 & 1 & 0 & 0 \\
\hline & 8 & 0 & 0 & 0 & 1 & 0 & 0 & 1 & 0 & 0 & 1 & 0 & 0 \\
\hline & 9 & 0 & 0 & 0 & 0 & 0 & 0 & 1 & 0 & 0 & 1 & 0 & 0 \\
\hline & 10 & 0 & 0 & 0 & 0 & 0 & 0 & 1 & 0 & 0 & 1 & 0 & 0 \\
\hline
\end{tabular}

Numbers indicate the grade of occlusal wear. Yellow indicates slight dentin caries. Red indicates expanded dentin caries. 

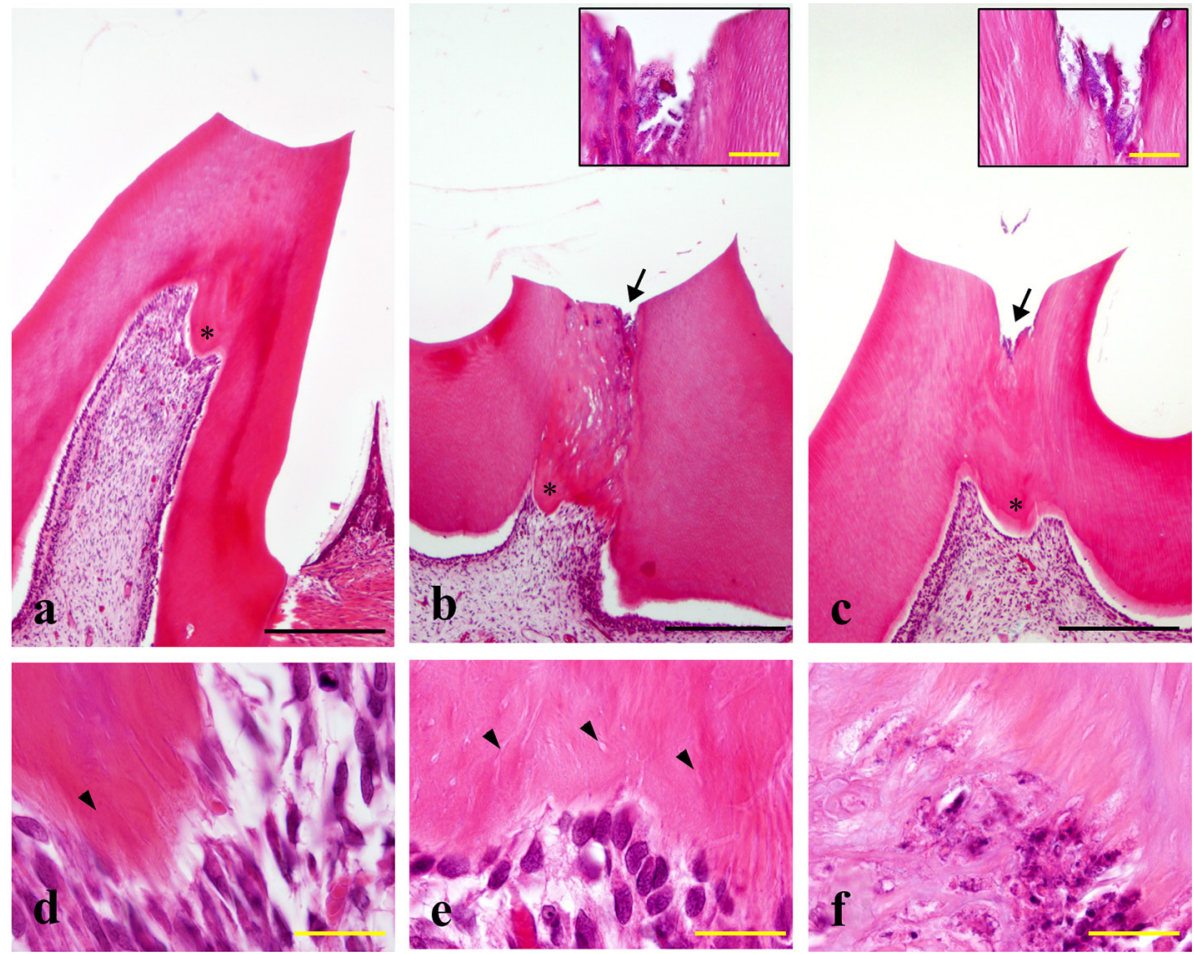

Fig. 7. Histopathological characteristics of molars. (a-c) Typical example of morphological changes in the Non-DM group (a) and DM group $(b, c)$. The inset is an enlarged view of the arrow. (a) No caries. Reparative dentin is formed in part of the cusp (asterisk). (b) Mild dental caries (arrow, inset). The occlusal surface is roughened by micro-defects of dentin with bacterial infection (arrow, inset). Reparative dentin is formed in part of the cusp (asterisk). (c) Advanced dental caries (arrow, inset). Expanded collapse with partial caving of the occlusal surface is observed (arrow, inset). Reparative dentin is formed in a part of the cusp (asterisk). (d-f) Typical example of the morphological changes in the dentin-pulp junction of the Non-DM group (d) and the DM group (e, f). (d) Disappearance of the predentin layer (arrowhead) and irregular arrangement of odontoblasts can be observed. (e) The dentinal tubule is tortuous or unclear (arrowheads). Hypertrophic odontoblasts are also observed. (f) Abscess and necrosis of the dental pulp are observed. Black scale bar $=250 \mu \mathrm{m}$. Yellow scale bar $=20 \mu \mathrm{m}$. HE stain.

Table 4. Incidence of Histopathologic Reparative Dentin and Presence of Bacteria in the Molars

\begin{tabular}{|c|c|c|c|c|}
\hline \multirow[b]{2}{*}{ Group } & \multicolumn{2}{|c|}{$\mathrm{DM}(\mathrm{n}=13)$} & \multicolumn{2}{|c|}{ Non-DM $(\mathrm{n}=10)$} \\
\hline & $\begin{array}{c}\text { Maxillary } \\
\text { molars }\end{array}$ & $\begin{array}{l}\text { Mandibular } \\
\text { molars }\end{array}$ & $\begin{array}{c}\text { Maxillary } \\
\text { molars }\end{array}$ & $\begin{array}{l}\text { Mandibular } \\
\text { molars }\end{array}$ \\
\hline No. examined & 78 & 78 & 60 & 60 \\
\hline Reparative dentin & $78(100 \%)$ & $76(97.4 \%)$ & $56(93.3 \%)$ & $58(96.7 \%)$ \\
\hline Presence of bacteria in dentinal tubule & $62(79.5 \%) * *$ & $60(76.9 \%) * *$ & $18(30.0 \%)$ & $28(46.7 \%)$ \\
\hline
\end{tabular}

Significant difference compared with the Non-DM group $(* * \mathrm{P}<0.01)$.

Table 5. Incidence and Grading of Vacuolation of the Acinar Cells in Each Salivary Gland

\begin{tabular}{|c|c|c|c|c|c|c|}
\hline \multirow[b]{2}{*}{ Group } & \multicolumn{2}{|c|}{ Parotid gland } & \multicolumn{2}{|c|}{ Von Ebner's gland } & \multicolumn{2}{|c|}{ Submandibular gland } \\
\hline & $\begin{array}{c}\mathrm{DM} \\
(\mathrm{n}=13)\end{array}$ & $\begin{array}{c}\text { Non-DM } \\
(\mathrm{n}=10)\end{array}$ & $\begin{array}{c}\text { DM } \\
(\mathrm{n}=13)\end{array}$ & $\begin{array}{c}\text { Non-DM } \\
(\mathrm{n}=10)\end{array}$ & $\begin{array}{c}\mathrm{DM} \\
(\mathrm{n}=13)\end{array}$ & $\begin{array}{c}\text { Non-DM } \\
(\mathrm{n}=10)\end{array}$ \\
\hline Incidence & $13(100 \%)$ & $3(30.0 \%)$ & $13(100 \%)$ & $4(40.0 \%)$ & $13(100 \%)$ & $10(100 \%)$ \\
\hline Grade 0 & 0 & $7(70.0 \%)$ & 0 & $6(60.0 \%)$ & 0 & 0 \\
\hline Grade 1 & $1(7.7 \%)$ & $3(30.0 \%)$ & 0 & $3(30.0 \%)$ & $9(69.2 \%)$ & $6(60.0 \%)$ \\
\hline Grade 2 & $2(15.4 \%)$ & 0 & $1(7.7 \%)$ & $1(10.0 \%)$ & $2(15.4 \%)$ & $2(20.0 \%)$ \\
\hline Grade 3 & $6(46.1 \%)$ & 0 & 0 & 0 & $2(15.4 \%)$ & $1(10.0 \%)$ \\
\hline Grade 4 & $4(30.8 \%)$ & 0 & $12(92.3 \%)$ & 0 & 0 & $1(10.0 \%)$ \\
\hline Mean score & $3.0 * *$ & 0.3 & $3.8 * *$ & 0.5 & 1.5 & 1.7 \\
\hline
\end{tabular}

Significant difference compared with the Non-DM group $(* * \mathrm{P}<0.01)$. 


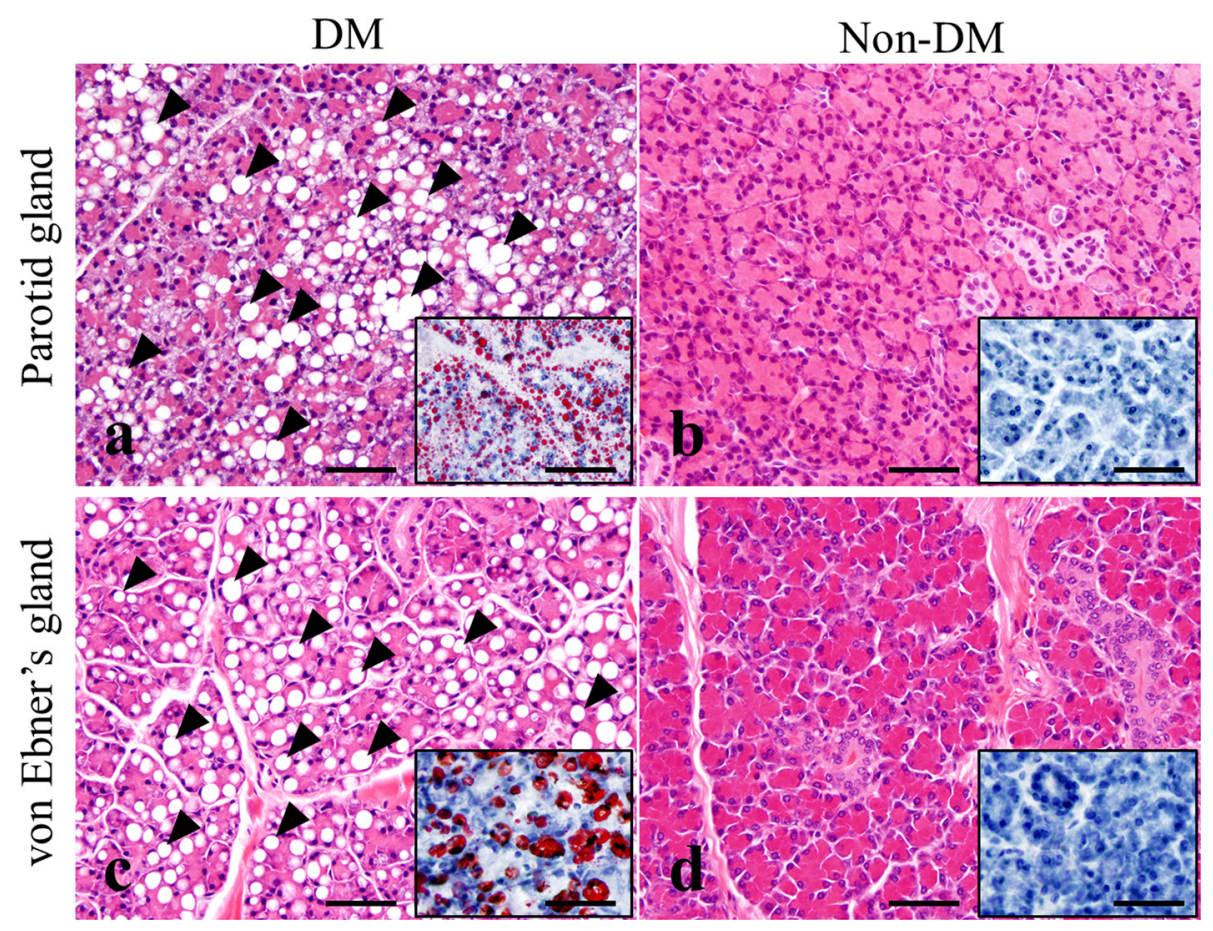

Fig. 8. Histopathological changes in the parotid and von Ebner's glands in the DM and Non-DM groups. (a, b) Parotid. (a) Typical example of vacuolation (Grade 4) of the acinar cells of the parotid gland in the DM group (arrowheads). Vacuoles are positive for Oil Red O stain (inset). (b) Normal parotid gland in the Non-DM group. (c, d) Von Ebner's glands. (c) Typical example of vacuolation (Grade 4) of the acinar cells of the von Ebner's gland in the DM group (arrowheads). Vacuoles are positive for Oil Red O stain (inset). (d) Normal von Ebner's gland in the Non-DM Group. Scale bar (a-d, inset) $=50 \mu \mathrm{m}$. HE stain. Oil Red O stain (inset).

nificantly higher than in the Non-DM group (Table 5). The vacuolation of the DM group progressed from focal lesions with a few small vacuoles to diffuse lesions with numerous small and large vacuoles. Some cells contained a large well-defined single round vacuole similar to a white adipocyte (Fig. 8a, 8c). The vacuoles were stained with Oil Red O (Fig. 8a, 8c inset). Mild vacuolation of the acinar cells in the submandibular gland was also observed, but there was no clear difference between the DM and Non-DM groups (Table 5). In addition, there was no difference in the size of the acinar cells of the salivary glands between the two groups.

\section{Discussion}

Long-lasting hyperglycemia inevitably induces dental caries in both chemically induced and spontaneous diabetic rodent models ${ }^{3,4,13}$. However, there are few reports regarding the initial formation of the dental caries in these diabetic models. In our previous study, progressive molar caries were induced in diabetic rats 13 weeks after alloxan administration $^{13}$. The dental caries in these diabetic models reach the dental pulp from the dentin surface, develop into pulpitis with bacterial colonization, and expand through the entire crown or to the dental root, thereby destroying the crown ${ }^{13,17}$. On the other hand, development of dental caries has not been reported yet in rats 1 month after AL treatment $^{18}$. Therefore, in this study, to investigate the process of initial caries formation, the autopsy point was set at 7 weeks after AL treatment, which corresponded to approximately half the time taken to reach the symptomatic stages of the dental caries. The present study revealed that the initial lesion of the dental caries, which appeared as micro-defects in dentin with bacterial colonization on the molar surface, could be identified using histopathological analysis, but not stereomicroscopic analysis, after 7 weeks of hyperglycemia.

We hypothesized that salivary gland dysfunction, which is one of the most important factors in the development of dental caries, might be latent before the initial formation of the dental caries in diabetic rats. The present study revealed that pilocarpine-induced saliva secretion in diabetic rats gradually decreased with continuous hyperglycemia starting immediately after AL treatment up to the point of autopsy when the dental caries were initially formed. Furthermore, large Oil Red O-positive lipid droplets accumulated in the acinar cells of the parotid glands in these diabetic rats. AL- and streptozotocin (STZ)-induced diabetic rats reportedly show a significant reduction in muscarinic agonist-induced salivary fluid secretion, such as in the case of pilocarpine, from 2 weeks to 6 weeks after the onset of hyperglycemia ${ }^{8,12,19,20}$. In addition, in rats, small lipid droplets were observed in the acinar cells of the parotid glands $24 \mathrm{~h}$ after STZ treatment, and lipid accumulation progressed and large lipid droplets appeared at 4.5 months after STZ treatment ${ }^{21,22}$. The point of onset of salivary gland 
dysfunction and the resultant morphological changes in hyperglycemia status were in agreement with our findings in this study.

Serous saliva secretion is induced by the muscarinic receptor stimulation ${ }^{23}$, and serous saliva is secreted into the oral cavity mainly from the parotid and submandibular glands ${ }^{24}$. In this study, saliva secretion induced by muscarinic receptor stimulation was remarkably reduced in the DM group, and morphological abnormalities were observed in the parotid glands but not in the submandibular glands. In rats, the parotid duct opens opposite the molar teeth ${ }^{25}$, and the effect of selective removal of the salivary glands on the incidence of dental caries was highest when the parotid glands were removed compared with that after removal of the other major salivary glands ${ }^{26}$. Thus, parotid gland dysfunction may be involved in the initial development of molar dental caries in AL-induced diabetic rats. Interestingly, in the Non-DM group, bacteria were present in the dentinal tubules of the molar surfaces, and minute collapse of the dentin with bacterial colonization appeared in a few cases; however, these changes were apparently enhanced in the DM group. These findings suggest that the salivary functions such as flushing of bacteria and remineralization of enamel and dentin by saliva ${ }^{27,28}$ may constantly protect the teeth against bacterial infection in normal rats and that hyposalivation caused by hyperglycemia may inhibit these salivary defensive functions against caries formation in ALinduced diabetic rats.

In the present study, we discovered that hyperglycemia caused the development of the dental caries and enhanced occlusal surface wear in AL-induced diabetic rats. In rodents, enamel does not exist at the occlusal surface of the cusp of the molar teeth ${ }^{29}$, and occlusal wear spontaneously progresses with age after the eruption of tooth buds $\mathrm{s}^{30-32}$. The histological findings of mild tortuosity of the dentinal tubules in the Non-DM group was consistent with that reported in a previous study on occlusal wear due to aging in young intact rats ${ }^{33}$. In the DM group, progressive molar occlusal wear stereoscopically formed a mortar-like shape, where histologically severe tortuosity and disappearance of the dentinal tubules were observed and the cusp height was morphometrically half that in the Non-DM group. From these findings, it is evident that the occlusal surface wear was further enhanced by hyperglycemia in the DM group. In addition, the odontoblast reaction and disarrangement in the pulp reportedly occur with occlusal wear in rats ${ }^{33}$, and these changes may have been similarly elicited by enhanced occlusal wear in the DM group in this study.

The pathogenesis of spontaneous occlusal surface wear mainly depends on mastication in both humans and rats ${ }^{31,32 \text {, }}$ 34. Diabetic animals consume a lot of food ${ }^{35,36}$, and in this study, food intake in the DM group was significantly greater than that in the Non-DM group. Thus, increase in food intake may naturally increase mastication in diabetic rats. In addition, saliva is a lubricant that reduces friction between the dental occlusal surfaces during mastication ${ }^{34}$. In the diabetic rats in the present study, hyposalivation and increased mastication may have increased the friction, thereby resulting in progressive occlusal surface wear. Furthermore, a number of mineral ions and antibacterial proteins in the saliva reportedly fluctuate in diabetic patients ${ }^{37-39}$. It is possible that remarkable hyposalivation in the diabetic rats in this study caused quantitative changes in salivary electrolytes and antibacterial proteins, inducing failure of tooth remineralization or caries formation. The hyperglycemic condition suppresses the formation of enamel and dentin in STZ-induced diabetic rats ${ }^{40}$. In AL-induced diabetic rats, metabolic disturbance caused by hyperglycemia could directly weaken the tooth substance, thereby enhancing occlusal surface wear as well as formation of dental caries.

In conclusion, hyperglycemia simultaneously induces initial caries development and enhances spontaneous occlusal surface wear of the molars in rats 7 weeks after alloxan treatment. The parotid gland dysfunction caused by hyperglycemia may be involved in the pathogenesis of occlusal wear as well as in dental caries in this diabetic model.

Acknowledgments: The authors wish to acknowledge Dr. Hiroyuki Akagi, Professor of the Laboratory of Molecular and Cellular Pharmacology, Hiroshima International University, for his kind support of this study.

Disclosure of Potential Conflicts of Interest: The authors declare that they have no conflicts of interest.

\section{References}

1. Keyes PH. Recent advances in dental caries research bacteriology. Bacteriological findings and biological implications. Int Dent J. 12: 443-464. 1962.

2. Fukuzato Y, Matsuura T, Ozaki K, Matsuura M, Sano T, Nakahara Y, Kodama Y, Nakagawa A, Okamura S, Suido H, Torii K, Makino T, and Narama I. Morphological study on dental caries induced in WBN/KobSlc rats (Rattus norvegicus) fed a standard laboratory diet. Lab Anim. 43: 376381. 2009. [Medline] [CrossRef]

3. Kodama Y, Matsuura M, Sano T, Nakahara Y, Ozaki K, Narama I, and Matsuura T. Diabetes enhances dental caries and apical periodontitis in caries-susceptible WBN/KobSlc rats. Comp Med. 61: 53-59. 2011. [Medline]

4. Sano T, Matsuura T, Ozaki K, and Narama I. Dental caries and caries-related periodontitis in type 2 diabetic mice. Vet Pathol. 48: 506-512. 2011. [Medline] [CrossRef]

5. Mohammadi N, Seyednejad F, Oskoee PA, Savadi Oskoee $\mathrm{S}$, and Ebrahimi Chaharom ME. Evaluation of radiationinduced class $\mathrm{v}$ dental caries in patients with head and neck cancers undergoing radiotherapy. J Dent Res Dent Clin Dent Prospect. 2: 82-84. 2008. [Medline]

6. Ooshima T, Hashida T, Fuchihata H, Fujiwara T, Yoshida T, and Izumitani A. Effect of experimental hyposalivation on the induction of dental caries in rats infected with Streptococcus mutans. Caries Res. 24: 446-451. 1990. [Medline] [CrossRef]

7. Pedersen AM, Reibel J, Nordgarden H, Bergem HO, Jensen JL, and Nauntofte B. Primary Sjögren's syndrome: salivary gland function and clinical oral findings. Oral Dis. 5: 128- 
138. 1999. [Medline] [CrossRef]

8. Anderson LC. Parotid gland function in streptozotocin-diabetic rats. J Dent Res. 66: 425-429. 1987. [Medline] [CrossRef]

9. Jawed M, Shahid SM, Qader SA, and Azhar A. Dental caries in diabetes mellitus: role of salivary flow rate and minerals. J Diabetes Complications. 25: 183-186. 2011. [Medline] [CrossRef]

10. Lasisi TJ, and Fasanmade AA. Salivary flow and composition in diabetic and non-diabetic subjects. Niger J Physiol Sci. 27: 79-82. 2012. [Medline]

11. Moore PA, Guggenheimer J, Etzel KR, Weyant RJ, and Orchard T. Type 1 diabetes mellitus, xerostomia, and salivary flow rates. Oral Surg Oral Med Oral Pathol Oral Radiol Endod. 92: 281-291. 2001. [Medline] [CrossRef]

12. Watanabe M, Yamagishi-Wang H, and Kawaguchi M. Lowered susceptibility of muscarinic receptor involved in salivary secretion of streptozotocin-induced diabetic rats. Jpn J Pharmacol. 87: 117-124. 2001. [Medline] [CrossRef]

13. Nakahara Y, Sano T, Kodama Y, Ozaki K, and Matsuura T. Alloxan-induced hyperglycemia causes rapid-onset and progressive dental caries and periodontitis in F344 rats. Histol Histopathol. 27: 1297-1306. 2012. [Medline]

14. Anderson LC. Effects of alloxan diabetes and insulin in vivo on rat parotid gland. Am J Physiol. 245: G431-G437. 1983. [Medline]

15. Reuterving CO. Pilocarpine-stimulated salivary flow rate and salivary glucose concentration in alloxan diabetic rats. Influence of severity and duration of diabetes. Acta Physiol Scand. 126: 511-515. 1986. [Medline] [CrossRef]

16. Reuterving CO, Hägg E, Henriksson R, and Holm J. Salivary glands in long-term alloxan-diabetic rats. A quantitative light and electron-microscopic study. Acta Pathol Microbiol Immunol Scand [A]. 95: 131-136. 1987. [Medline]

17. Nakahara Y, Ozaki K, Sano T, Kodama Y, and Matsuura T. Assessment of alloxan-induced diabetic rats as a periodontal disease model using a selective cyclooxygenase (COX)2 inhibitor. J Toxicol Pathol. 27: 123-129. 2014. [Medline] [CrossRef]

18. Reuterving CO, Hägg E, and Gustafson GT. Root surface caries and periodontal disease in long-term alloxan diabetic rats. J Dent Res. 65: 689-694. 1986. [Medline] [CrossRef]

19. Fedirko NV, Kruglikov IA, Kopach OV, Vats JA, Kostyuk PG, and Voitenko NV. Changes in functioning of rat submandibular salivary gland under streptozotocin-induced diabetes are associated with alterations of $\mathrm{Ca}^{2+}$ signaling and $\mathrm{Ca}^{2+}$ transporting pumps. Biochim Biophys Acta. 1762: 294-303. 2006. [Medline] [CrossRef]

20. Romero AC, Ibuki FK, and Nogueira FN. Sialic acid reduction in the saliva of streptozotocin induced diabetic rats. Arch Oral Biol. 57: 1189-1193. 2012. [Medline] [CrossRef]

21. Anderson LC, and Garrett JR. Lipid accumulation in the major salivary glands of streptozotocin-diabetic rats. Arch Oral Biol. 31: 469-475. 1986. [Medline] [CrossRef]

22. Hand AR, and Weiss RE. Effects of streptozotocin-induced diabetes on the rat parotid gland. Lab Invest. 51: 429-440. 1984. [Medline]

23. Ishikawa $Y$, and Ishida $H$. Aquaporin water channel in salivary glands. Jpn J Pharmacol. 83: 95-101. 2000. [Medline] [CrossRef]

24. Delporte C, Bryla A, and Perret J. Aquaporins in salivary glands: from basic research to clinical applications. Int J Mol Sci. 17: 166. 2016. [Medline] [CrossRef]

25. Navia JM, Baker HJ, Bernard B, Keele J, Lemons JE, Travis BJ, and Volker JF. Animal models in dental research. The University of Alabama Press, Tuscaloosa. 226-227. 1977.

26. Schwartz A, and Shaw JH. Studies on the effect of selective desalivation on the dental caries incidence of albino rats. J Dent Res. 34: 239-247. 1955. [Medline] [CrossRef]

27. Reich E, Lussi A, and Newbrun E. Caries-risk assessment. Int Dent J. 49: 15-26. 1999. [Medline] [CrossRef]

28. Ship JA, Pillemer SR, and Baum BJ. Xerostomia and the geriatric patient. J Am Geriatr Soc. 50: 535-543. 2002. [Medline] [CrossRef]

29. Yamamoto H, and Nawa T. Enamel free areas in rodent molars--ultrastructure of basement membrane in rat tooth germ. Int J Dev Biol. 39: 163-168. 1995. [Medline]

30. Lovschall H, Fejerskov O, and Josephsen K. Age-related and site-specific changes in the pulpodentinal morphology of rat molars. Arch Oral Biol. 47: 361-367. 2002. [Medline] [CrossRef]

31. Nishijima K, Kuwahara S, Ohno T, Miyaishi O, Ito Y, Sumi $\mathrm{Y}$, and Tanaka S. Occlusal tooth wear in female F344/N rats with aging. Arch Oral Biol. 52: 844-849. 2007. [Medline] [CrossRef]

32. Nishijima K, Kuwahara S, Ohno T, Miyaishi O, Ito Y, Sumi $\mathrm{Y}$, and Tanaka S. Occlusal tooth wear in male F344/N rats with aging. Arch Gerontol Geriatr. 48: 178-181. 2009. [Medline] [CrossRef]

33. Mahdee A, Alhelal A, Eastham J, Whitworth J, and Gillespie JI. Complex cellular responses to tooth wear in rodent molar. Arch Oral Biol. 61: 106-114. 2016. [Medline] [CrossRef]

34. d'Incau E, Couture C, and Maureille B. Human tooth wear in the past and the present: tribological mechanisms, scoring systems, dental and skeletal compensations. Arch Oral Biol. 57: 214-229. 2012. [Medline] [CrossRef]

35. Lee SM, and Bressler R. Prevention of diabetic nephropathy by diet control in the $\mathrm{db} / \mathrm{db}$ mouse. Diabetes. 30: 106-111. 1981. [Medline] [CrossRef]

36. Tesseromatis C, Kotsiou A, Parara H, Vairaktaris E, and Tsamouri M. Morphological changes of gingiva in streptozotocin diabetic rats. Int J Dent. 2009: 725628. 2009. [Medline] [CrossRef]

37. Jawed M, Khan RN, Shahid SM, and Azhar A. Protective effects of salivary factors in dental caries in diabetic patients of Pakistan. Exp Diabetes Res. 2012: 947304. 2012. [Medline] [CrossRef]

38. Mata AD, Marques D, Rocha S, Francisco H, Santos C, Mesquita MF, and Singh J. Effects of diabetes mellitus on salivary secretion and its composition in the human. Mol Cell Biochem. 261: 137-142. 2004. [Medline] [CrossRef]

39. Zalewska A, Knaś M, Kuźmiuk A, Waszkiewicz N, Niczyporuk M, Waszkiel D, and Zwierz K. Salivary innate defense system in type 1 diabetes mellitus in children with mixed and permanent dentition. Acta Odontol Scand. 71: 1493-1500. 2013. [Medline] [CrossRef]

40. Abbassy MA, Watari I, Bakry AS, Hamba H, Hassan AH, Tagami J, and Ono T. Diabetes detrimental effects on enamel and dentine formation. J Dent. 43: 589-596. 2015. [Medline] [CrossRef] 